\title{
Maternal and Fetal Outcomes Following Caesarean Section in Comprehensive Emergency Obstetric Care Program at Nuwakot District Hospital
}

\author{
Bhandari BR \\ Department of Obstetrics and Gynaecology, MIDAT Hospital, Lalitpur, Nepal
}

Received: June 12, 2015 ; Accepted: December 5, 2015

Aims: This study was conducted to assess the fetal and maternal outcomes following cesarean section in Trishuli District Hospital at Nuwakot, Nepal.

Methods: A hospital based study was conducted in Trishuli District Hospital Nuwakot from $14^{\text {th }}$ March 2012 to $13^{\text {th }}$ March 2013 among 327 pregnant women who underwent cesarean section in Trishuli District Hospital Nuwakot and met the inclusion criteria of this study.

Results: The most common indication of caesarean section was $(n=139,42.6 \%)$ foetal distress $(n=98,30 \%$ moderate to thick meconium stained liquor; $\mathrm{n}=41,12.6 \%$ foetal tachybradycardia). Among maternal complications, wound infections was seen in seven $(2.1 \%)$ pregnant women, uterine rupture in two $(0.6 \%)$, post partum haemorrhage in one $(0.3 \%)$, post partum eclampsia in one $(0.3 \%)$ and peurperial pyrexia in one $(0.3 \%)$. Among perinatal complications, birth asphyxia was present in $10(3 \%)$ neonates, neonatal sepsis in seven $(2 \%)$ and perinatal death in $12(3.5 \%)$ neonates.

Conclusions: Better BEmOC reduced the number of $\mathrm{CEmOC}$ requirement. Providing $\mathrm{CEmOC}$ in district level is the vital measure in safe motherhood for reducing maternal and perinatal morbidities and mortalities. But for improving maternal and perinatal outcomes in district level, there should be adequate skilled manpower in maternity ward and operation theature, adequate infrastructures in preoperative, operative and postoperative wards, blood bank and neonatal high dependency unit in CEmOC.

Keywords: comprehensive emergency obstetric care; maternal outcome; perinatal outcome.

\section{INTR ODUCTION}

Nepal has made satisfactory progress in many areas of health and social development. In 1996, high maternal mortality of 539 per 100,000 live births remains a major challenge for the country. Government of Nepal, having had endorsed the Millennium Declaration (2001) remains committed to the achievement of Millennium Development Goals (MDG), which requires reduction of maternal mortality ratio (MMR) by two thirds (129-213/100,000 live births), by $2015 .^{1}$

Although Nepal's health system has experienced nearly 10 years of severe disruption caused by armed conflict, the country managed to almost halve its MMR from 539 deaths per 100,000 live births for 1989-1995 to 281 deaths per 100,000 live births for 1999-2005. Even with this progress, one woman was dying every four hours as a result of pregnancy

\section{CORRESPONDENCE}

Dr Binaya Raj Bhandari

Department of Obstetrics and Gynaecology

MIDAT Hospital Lalitpur, Nepal.

Email: bhandaribinaya9@gmail.com

Phone: +977-9841759010 and childbirth. Most maternal deaths were a direct consequence of under-utilization of appropriate health services and low quality of care, especially in rural areas. Other factors included traditional beliefs held by women, their families and communities and the lack of awareness of services and their utilization. ${ }^{2}$

Comprehensive Emergency Obstetric Care (CEmOC) comprises all component of basic emergency obstetric care (BEmOC) along with surgery (cesarean section and laparotomy) and blood transfusion. It is recognized that only access to EmOC can substantially reduce maternal mortality rate. ${ }^{3}$

Caesarean section is defined as delivery of the fetus, alive or dead, through incision in the abdominal wall and the uterine wall. Improved anaesthetic techniques and antiseptic procedures have revolutionized modern obstetrics practice. ${ }^{4}$

The World Health Organization (WHO) estimates that globally, between four and nine million newborns suffer birth asphyxia each year. Birth asphyxia leads to an estimated 1.2 million deaths and about the same number of infants who develop severe consequences, such as epilepsy, cerebral palsy, and developmental delay. WHO estimates for global neonatal deaths 
caused by birth asphyxia are $29 \% .{ }^{5}$

CEmOC is very much important component of health system for reducing maternal and neonatal morbidity as well as mortality in district level of Nepal. This study aimed to assess the maternal and neonatal outcomes in pregnant women who had come for CEmOC sevice in Nuwakot.

\section{METHODS}

A hospital based study was carried out in Trishuli District Hospital Nuwakot from 14 ${ }^{\text {th }}$ March 2012 to $13^{\text {th }}$ March 2013. Three hundred and twenty seven pregnant women who presented to labour room for management of late pregnancy and different stages of labour were included for the study. Women with complicated pregnancy need referral to higher center for further management and women who did not give informed consent were excluded from the study.

Ethical clearance for the study was taken from administration of Nuwakot district hospital. Informed consents were taken from the participants.

All women who had undergone caesarean section and fulfilling the inclusion criteria were enrolled for the study. Age, address, ethnicity, caste, parity, period of gestation, obstetric history, labour events, indications for caesarean section, operative complications, post- operative complications and duration of hospitalization were recorded in maternal data. Number of baby, sex of baby, birth weight, colour of liquor, one and five minute APGAR scores, need for resuscitation, referral to neonatal intensive care unit, neonatal complications and duration of hospitalization were documented in neonatal data. Questionnare was reviewed thoroughly for accuracy, completeness and consistency. A master table and quantitative data were entered and analysed using Statistical Package for Social Studies (SPSS) version 15.

\section{RESULTS}

During the study period of 12 months, 327 women who had undergone caesarean section were included in the study. Almost 90.2\% pregnant women were from Nuwakot, $4.9 \%$ from Rasuwa, 1.8\% from Dhading and 3\% from other district of Nepal. The mean age of pregnant women was $23 \pm 4.29$ years with minimum age of 16 years and maximum age of 40 years. Approximately $42.5 \%$ were disadvantaged janajatis, 36.5\% upper caste group, $14.5 \%$ relatively advantaged janajatis and $6.5 \%$ were dalit by ethnicity. About $63.6 \%$ pregnant women were primigravida and $21.1 \%$ were second gravida. Seventy seven percent women presented to labour room between 37 to 41 weeks, $17.7 \%$ at $>41$ weeks and $5.3 \%$ at $<37$ weeks of period of gestation. Around $84 \%$ pregnant women had cephalic presentation, $10.4 \%$ breech presentation, $2 \%$ twin pregnancy, $2.5 \%$ shoulder presentation and $1 \%$ face presentation (Table 1 ).

Table 1. Characteristics of pregnant women based on address, age, ethnicity, parity, period of gestation and presentation.

\begin{tabular}{|c|c|c|}
\hline Characteristics & Number & $\%$ \\
\hline \multicolumn{3}{|l|}{ Address } \\
\hline Nuwakot & 295 & 90.2 \\
\hline Rasuwa & 16 & 4.9 \\
\hline Dhading & 6 & 1.8 \\
\hline Others & 10 & 3 \\
\hline \multicolumn{3}{|l|}{ Age in years } \\
\hline $15-19$ years & 55 & 16.8 \\
\hline $20-24$ years & 157 & 48 \\
\hline 25-29 years & 86 & 26.3 \\
\hline $30-34$ years & 21 & 6.4 \\
\hline $35-39$ years & 6 & 1.8 \\
\hline$\geq 40$ years & 2 & 0.6 \\
\hline \multicolumn{3}{|l|}{ Ethnicity } \\
\hline Dalit & 19 & 5.8 \\
\hline Disadvantaged Janajatis & 139 & 42.5 \\
\hline Religious minorities & 2 & 0.6 \\
\hline $\begin{array}{l}\text { Relatively advantaged } \\
\text { Janajatis }\end{array}$ & 47 & 14.4 \\
\hline Upper caste & 120 & 36.7 \\
\hline \multicolumn{3}{|l|}{ Parity } \\
\hline Primigravida & 208 & 63.6 \\
\hline Multigravida & 119 & 36.4 \\
\hline \multicolumn{3}{|l|}{ Period of Gestation } \\
\hline$<37$ weeks & 17 & 5.3 \\
\hline $37-41$ weeks & 252 & 77 \\
\hline$>41$ weeks & 58 & 17.7 \\
\hline \multicolumn{3}{|l|}{ Presentation } \\
\hline Cephalic & 275 & 84.1 \\
\hline Breech & 34 & 10.4 \\
\hline Twin & 7 & 2.1 \\
\hline $\begin{array}{l}\text { Transverse lie with } \\
\text { Shoulder presentation }\end{array}$ & 8 & 2.4 \\
\hline Face & 3 & 1 \\
\hline
\end{tabular}


The indications of caesarean section were foetal distress in $139(42.6 \%) \quad\{98(30 \%)$ moderate to thick meconium stained liquor, 41 (12.6\%) foetal tachybradycardia\}, failed induction in $49(15 \%)$, abnormal presentation in $48(14.6 \%)$, severe oligohydramnion in $26(8 \%)$, bad obstetrics history in $16(5 \%)$, non-progress of labour in $16(5 \%)$, cephalopelvic disproportion in $12(3.6 \%)$, prolonged second stage of labour in $10(3 \%)$, antepartum haemorrhage in $7(2 \%)$ and intrauterine growth retardation in $4(1.2 \%)\{$ Table 2$\}$.

Table 2. Indications of Caesarean section.

\begin{tabular}{|lll|}
\hline Indications & Number & Frequency \\
\hline Foetal distress & 139 & 42.6 \\
Failed induction & 49 & 15 \\
$\begin{array}{l}\text { Abnormal } \\
\text { presentation }\end{array}$ & 48 & 14.6 \\
$\begin{array}{l}\text { Severe } \\
\text { oligohydramnion }\end{array}$ & 26 & 8 \\
$\begin{array}{l}\text { Bad obstetrics } \\
\text { history }\end{array}$ & 16 & 5 \\
$\begin{array}{l}\text { Non progress } \\
\text { of labour }\end{array}$ & 16 & 5 \\
$\begin{array}{l}\text { Cephalopelvic } \\
\text { disproportion }\end{array}$ & 12 & 3.6 \\
$\begin{array}{l}\text { Prolonged second } \\
\text { stage of labour }\end{array}$ & 10 & 3 \\
$\begin{array}{l}\text { Antepartum } \\
\text { haemorrhage }\end{array}$ & 7 & 2 \\
$\begin{array}{l}\text { Intrauterine } \\
\text { growth retardation }\end{array}$ & 4 & 1.2 \\
\hline
\end{tabular}

Among caesarean section, emergency caesarean section was in $292(89.2 \%)$ pregnant women, elective caesarean section in $34(10.5 \%)$, classical caesarean section in two $(0.61 \%)$ and emergency laparotomy with subtotal hysterectomy was done in one $(0.3 \%)$ pregnant women. There were $16(5 \%)$ pregnant women who had previous caesarean section done in the past. Bilateral tubal ligation was done in 50 (15.3\%) pregnant women who had received CEmOC service. There were two cases of uterine rupture, emergency laparotomy with repair of uterine rupture and bilateral tubal ligation done in one patient and emergency laparotomy with subtotal hysterectomy done in one patient. Along with $\mathrm{CS}$, enucleation of dermoid cyst was performed in 3 (1\%) pregnant women.

The mean days of hospital stay was $4 \pm 2.2$ days with ranges from 2-10 days. There was one patient referred to tertiary center for better management after emergency laparotomy with subtotal hysterectomy for obstructed labour with uterine rupture.

There were no maternal complications in 315 (96.43\%) women, seven women $(2.1 \%)$ developed wound infections, two women $(0.61 \%)$ uterine rupture, one women $(0.3 \%)$ post-partum haemorrhage, one women $(0.3 \%)$ post partum eclampsia and one women $(0.3 \%)$ developed peurperial pyrexia. Blood transfusion was required in two $(0.6 \%)$ women for severe blood loss. There was no maternal mortality among CEmOC clients during study period (Table 3 ).

Table 3. Maternal complications.

\begin{tabular}{|lll|}
\hline Maternal complications & Number & Frequency \\
\hline None & 315 & 96.43 \\
Wound infections & 7 & 2.1 \\
$\begin{array}{l}\text { Uterine rupture } \\
\text { Post partum } \\
\text { haemorrhage }\end{array}$ & 2 & 0.61 \\
$\begin{array}{l}\text { Post partum } \\
\text { eclampsia }\end{array}$ & 1 & 0.3 \\
$\begin{array}{l}\text { Post partum } \\
\text { peurperial pyrrexia }\end{array}$ & 1 & 0.3 \\
\hline
\end{tabular}

Seven women developed wound infection following caesarean section and only two women had undergone secondary suturing along with hospital readmission and intravenous antibiotics. 327 (98\%) babies were alive at birth. $170(51 \%)$ babies were male and 164 (49\%) were female. The mean birth weight of babies was $3160 \pm 455$ grams with minimum weight of 1400 grams and maximum weight of 4800 grams. There were 64 (19.1\%) babies who had low birth weight and five $(1.5 \%)$ babies had weight $\geq 4000$ grams. APGAR scores $>5 / 10$ was seen in $298(89.2 \%)$ babies, $>3$ to $\leq 5 / 10$ in $21(6.3 \%)$ babies, $\leq 3 / 10$ in eight $(2.5 \%)$ babies and 0/10 APGAR scores as seen in seven (2\%) babies (Table 4$)$. 
Table 4. Characteristics of babies at birth.

\begin{tabular}{|lll|}
\hline Characteristics & Number & \% \\
\hline Alive & 327 & 98 \\
Dead & 7 & 2 \\
Male & 170 & 50.9 \\
Female & 164 & 49.1 \\
Birth weight of baby & & \\
$\leq 1500$ grams & 3 & 0.9 \\
$>1500<2500$ grams & 61 & 18.2 \\
$2500-3500$ grams & 250 & 74.9 \\
$>3500<4000$ grams & 15 & 4.5 \\
$\geq 4000$ grams & 5 & 1.5 \\
APGAR Scores at $\mathbf{1}$ min & & \\
$>5 / 10$ & 298 & 89.2 \\
$>3 / 10$ to $\leq 5 / 10$ & 21 & 6.3 \\
$\leq 3 / 10$ & 8 & 2.5 \\
$0 / 10$ & 7 & 2 \\
\hline
\end{tabular}

There were no neonatal complications in 299 (89.5\%) babies, 10 (3\%) developed birth asphyxia, seven $(2 \%)$ neonatal sepsis, seven $(2 \%)$ stillbirth, five $(1.5 \%)$ neonatal death, two $(0.6 \%)$ congenital hydrocephalous, two $(0.6 \%)$ respiratory distress syndrome and two $(0.6 \%)$ babies developed meconium aspiration syndrome.

\section{DISCUSSION}

In this study, 264 (76\%) women were in the age group of 20-34 years with mean age of $23 \pm 4.29$ years, age less than 19 years were $55(16.8 \%)$ and age more than 35 years were found in eight $(2.5 \%)$. Muhammad et $\mathrm{al}^{4}$ found that $120(80 \%)$ women were in the age group of 20-30 years, 129 (86\%) were below the age of 30 years and $21(14 \%)$ were above the age of 30 years. $208(63.6 \%)$ were primigravidae and 109 (33.4\%) multigravidae and $10(3 \%)$ were grand multigravidae in this study. In contrast to this study, Mamoona et $\mathrm{al}^{6}$ showed that $116(21.40 \%)$ were primigravidae, 207 (38.19\%) multigravidae and 219 (40.41\%) were grand multigravidae.

Among indications of CS, The foetal distress was present in 139 (42.6\%) women, failed induction in 49 $(15 \%)$, abnormal presentation in $48(14.6 \%)$, severe oligohydramnion in $26(8 \%)$, non-progress of labour in $16(5 \%)$ and cephalopelvic disproportion in 12 (5\%) women. Nwosu et $\mathrm{al}^{7}$ reported that cephalopelvic disproportion with or without obstructed labour was seen in 528 (42\%) women, antepartum haemorrhage in $189(15.1 \%)$, foetal distress in $174(13.9 \%)$, hand prolapsed and transverse lie in $43(3.4 \%)$ and breech in $26(2.1 \%)$ women.

In this study, 315 (96.43\%) women had no maternal complications, seven (2.1\%) women developed wound infections, two $(0.61 \%)$ uterine rupture, one $(0.3 \%)$ post partum haemorrhage, one $(0.3 \%)$ post partum eclampsia and one $(0.3 \%)$ developed peurperial pyrexia. There was no maternal mortality among CEmOC clients during study period. Rehana et $\mathrm{al}^{8}$ reaveled that $21(11.8 \%)$ women developed wound infection, nine (5\%) had massive haemorrhage, caesarean hysterectomy was done in three (1.69\%) women having massive haemorrhage and there was one maternal death due to disseminated intravascular coagulation.

The mean birth weight of babies was $3160 \pm 455$ grams with minimum weight of 1400 grams and maximum weight of 4800 grams. There were 64 (19.1\%) babies who had low birth weight and five (1.5\%) babies had weight $\geq 4000$ grams. Roy et $\mathrm{al}^{9}$ found that the mean birth weight of babies underwent cesarean section for suspected foetal distress was $2805 \pm 350$ grams. Mean age was 3300 grams in the study conducted by Nwosu et $\mathrm{al}^{7}$.

APGAR scores at five minutes was $>5 / 10$ in 298 $(89.2 \%)$ babies, $>3$ to $\leq 5 / 10$ in $21(6.3 \%)$ babies, $\leq 3 / 10$ in eight $(2.5 \%)$ babies and $0 / 10$ in seven $(2 \%)$ babies. Nwosu et $\mathrm{al}^{7}$ reported that APGAR score at five minutes was $>7 / 10$ in $26.2 \%, 4-6 / 10$ in $46.3 \%$ and $1-3 / 10$ in $7.5 \%$. Nuaim et $\mathrm{al}^{10}$ reported that there were $91.4 \%$ babies had APGAR score $\geq 7 / 10$ and $8.5 \%$ babies had APGAR score $<6 / 10$ among emergency cesarean section group.

In this study, $299(89.5 \%)$ babies had no neonatal complications, 10 (3\%) developed birth asphyxia, seven $(2 \%)$ neonatal sepsis, seven $(2 \%)$ still birth, five $(1.5 \%)$ early neonatal death, two $(0.6 \%)$ congenital hydrocephalous, two $(0.6 \%)$ respiratory distress syndrome and two $(0.6 \%)$ babies developed meconium aspiration syndrome. Ezechi et al ${ }^{11}$ revealed that there were $6.9 \%$ perinatal mortality among caesarean section in South Western Nigeria, out of which $60.3 \%$ were still birth and $39.7 \%$ were early neonatal death. 


\section{CONCLUSIONS}

The most common indication of caesarean section was foetal distress. Majority of women had no maternal complications and there was no maternal mortality during study period. Majority of babies had no neonatal complications with minimal perinatal mortality. Better antenatal care and better BEmOC reduce caesarean section rate. Providing CEmOC in district level is the vital measure in safe motherhood for reducing maternal and perinatal morbidities and mortalities. But for better maternal and perinatal outcome, there should be adequate manpower in maternity ward and operation theature, adequate infrastructures in preoperative, operative and postoperative wards, blood bank and neonatal high dependency unit for CEmOC.

\section{DISCLOSURE}

The authors report no conflicts of interest in this work. No violation of human rights and safety.

Funding: Nil

\section{REFERENCES}

1. Department of community medicine and family planning IOM. Final report. Study on utilization of family emergency obstetric care-EmOC in selected district of Nepal; August 2004.

2. UNICEF health section program division. Innovative approaches to maternal and newborn health. Compendium of case studies; August 2013:36.

3. Joyce Abbatt. Nepal safer motherhood project. Challenges to reducing maternal mortality: experiences from three districts in the Nepal; August 1999: 176/96/DFID; 7-8

4. Ali M, Ahmad M, Rashida H. Maternal and fetal outcome comparison between emergency caesarean section versus elective caesarean section. Professional Med J. 2005;12(1):32-9.

5. Pitsawong C, Panichkul P. Risk factors associated with birth asphyxia in Phramongkutklao hospital. The Journal of Obstetrics and Gynaecology. 2011;19(4):165-71.

6. Mamoona R, Shaffiq A. An audit of caesarean section and its perinatal outcome. JPMI. 1994;8(2):29-33.
7. Nwosu C, Agumor K, Aboyeji AP, Ijaiya MA. Outcome of caesarean section in a sub-urban secondary health care facility in Nigeria. Niger Med Pract. 2004;46(7):77-9.

8. Najam R, Sharma R. Maternal and fetal outcomes in elective and emergency caesarean section at a teaching hospital in North India-a retrospective study. J Adv Res Biol Sci. 2013;5(1):5-9.

9. Raj KK, Baruah J, Kumar S, Deorwa AK, Sharma JB, Karmakar J. Caesarean section for suspected foetal birth asphyxia, continuous fetal heart monitoring and decision to delivery time. Indian Journal of Paediatrics. 2008;75(12):1249-52.

10. Nuaim LA, Seltain MH, Khashoggi T, Addar M, Chowdhary $\mathrm{N}$, Adelusi B. Outcome in elective and emergency caesarean section a comparative study. Ann Saudi Med. 1996;16(6):645-

11. Ezechi OC, Loto OM, Ndububa I, Okogbo FO, Ezeebi PM, Nwokoro LA. Caesarean section and perinatal mortality in south western Nigeria. NJOG. 2009;4(1):46-8. 